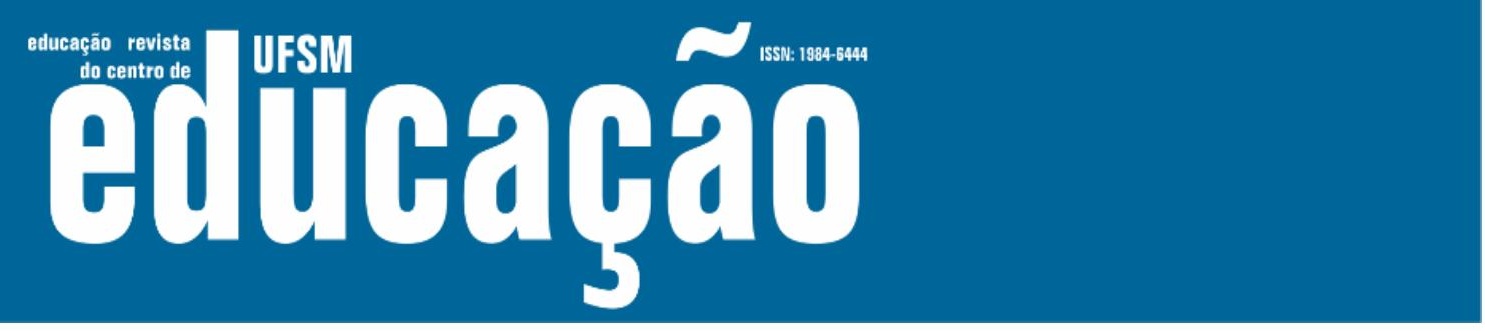

ISSN: 1984-6444 | http://dx.doi.org/10.5902/1984644439944

\title{
Experiências juvenis contemporâneas: reflexões teóricas e metodológicas sobre socialização e individualização
}

\author{
Contemporary Youth Experiences: Theoretical and Methodological \\ Reflections on Socialization and Individualization
}

Juliana Batista dos Reis

Professora adjunta na Universidade Federal de Minas Gerais, Belo Horizonte, Minas Gerais. Brasil. jubtr@yahoo.com.br - http://orcid.org/0000-0002-6477-5388

\section{Juarez Dayrell}

Professor aposentado da Universidade Federal de Minas Gerais, Belo Horizonte, Minas Gerais. Brasil. juareztd@gmail.com - https://orcid.org/0000-0001-7080-5662

Recebido em 10 de setembro de 2019

Aprovado em 26 de fevereiro de 2020

Publicado em 10 de agosto de 2020

\section{RESUMO}

Este artigo desenvolve reflexões teóricas e metodológicas para os estudos sobre juventudes na contemporaneidade diante da experiência de sujeitos imersos no universo online e digital. A partir de uma análise bibliográfica e sociológica sobre as noções de socialização e individualização, inclusive na internet, o texto reflete sobre os desafios para as pesquisas que buscam compreender a construção social dos/as jovens na atualidade, diante o atual processo estrutural de singularização e a intensa presença da internet como espaço de experiências juvenis. Conclui-se que a web é matriz de socialização que transversaliza o cotidiano de jovens em outras esferas de socialização familiar, escolar, entre pares. A partir de referências das sociologias do indivíduo e da sociologia da juventude, o ensaio estimula o desenvolvimento de um olhar para as experiências juvenis atrelando as categorias analíticas socialização e individualização a partir de plurais e interseccionados modos de ser e estar no mundo, no contexto da cibercultura.

Palavras-chave: Juventudes; Socialização; Individualização.

\section{ABSTRACT}

This article develops theoretical and methodological reflections for contemporary youth studies in face of the the experience of subjects immersed in the online and digital universe. From a sociological analysis on the notions of socialization and individualization, including on the internet, this text reflects on the challenges for research that seeks to understand the social construction of young people today, given the current structural process of singularization and the intense Internet presence as a 


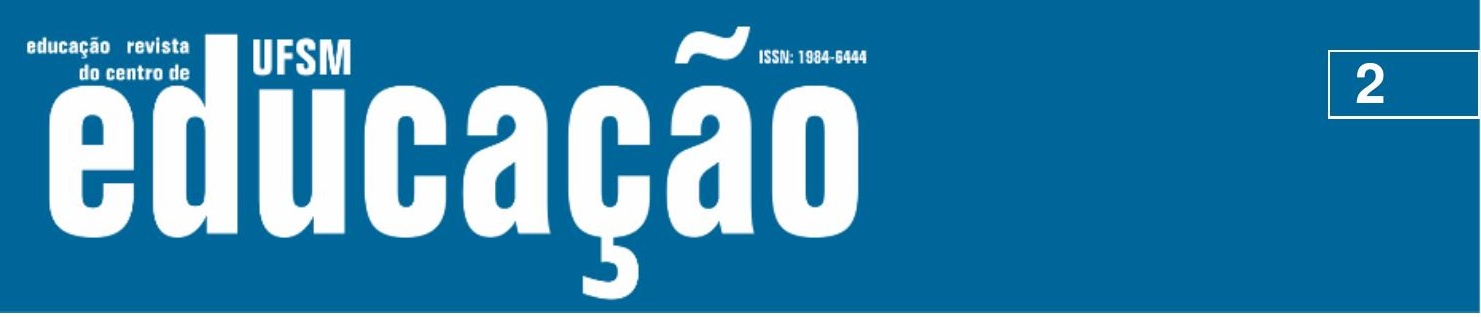

ISSN: 1984-6444 | http://dx.doi.org/10.5902/1984644439944

space for youth experiences. The web is understood as a matrix of socialization that cuts across the daily lives of young people in other spheres of socialization, such as family, school and among peers. Based on references from the sociologies of the individual and the sociology of youth, this essay stimulates the development of a look at youth experiences by linking the analytical categories socialization and individualization from plural and intersected ways of being and living in the world, in the context of cyberculture.

Keywords: Youths; Socialization; Individualization.

\title{
Introdução
}

\begin{abstract}
Quando Polegarzinha usa o computador ou celular, ambos exigem o corpo de uma motorista na tensão da atividade, e não o de um passageiro na passividade do relaxamento: demanda e não oferta. Ela arqueia as costas e não fica de barriga para cima. Empurre essa pessoinha para uma sala de aula: habituado para dirigir, seu corpo não suporta por muito tempo a poltrona do passageiro passivo. A Polegarzinha, então, se ativa, mesmo sem aparelho para dirigir. Algazarra. Ponha em suas mãos um computador e ela recupera os gestos do corpo-piloto. (SERRES, 2013, p. 50)
\end{abstract}

O filósofo francês Michel Serres expõe uma personagem contemporânea com enorme habilidade de mover seus dedos polegares para escrever mensagens nos aparelhos celulares. Para relatar os modos de ser, viver, sentir e pensar dos sujeitos imersos no universo online e digital, Serres nos apresenta Polegarzinha, nome que "não indica alguém de sua geração ou um adolescente de hoje, que são expressões de desprezo. Única, a Polegarzinha existe como indivíduo, como pessoa e não como abstração" (SERRES, 2013, p. 83), uma personagem de referência identitária marcada pela autonomia que exige constante performance para ser alguém (SIBILIA, 2018).

Além de um modo de ser ativo no ciberespaço, jovens como Polegarzinha podem ser vistos como agenciadores nos múltiplos e transversais espaços em que vivem. A metáfora empregada por Serres - uma motorista em ação e não uma passageira passiva - é também usada por José Machado Pais (2001) para dizer da intensa atividade dos/as jovens contemporâneos em suas trajetórias. O autor português adverte que a própria ideia de trajetória pode sinalizar a representação da vida em uma única linha, sendo que, ao contrário, a existência contemporânea se move pelas contingências, em um emaranhado de traços interseccionados. Pais 


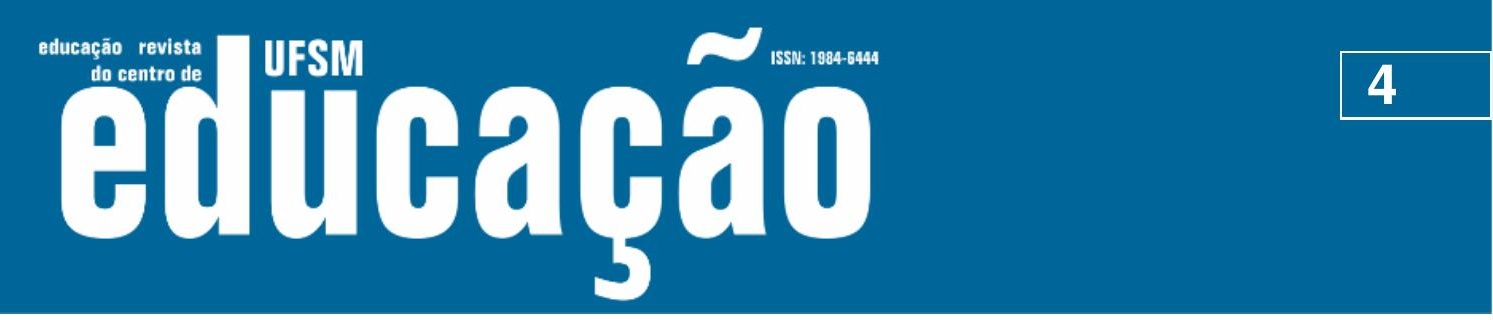

ISSN: 1984-6444 | http://dx.doi.org/10.5902/1984644439944

os modos de socialização e individualização².

Assim, em uma época em que "os indivíduos não cessam de singularizaremse" (MARTUCCELLI, 2007a, p.8), a web é tomada como espaço para os movimentos dessa singularização de jovens. Por isso,

\begin{abstract}
entendam por Polegarzinha um nome código para determinado estudante, paciente, operário, camponês, eleitor, transeunte, cidadão... anônimo, com certeza, mas individualizado. Nem tanto um eleitor contando como um nas pesquisas, nem tanto um telespectador contando como um no lbope, nem tanto uma quantidade, mas sim uma qualidade, uma existência. (SERRES, 2013, p. 85 - grifos do autor).
\end{abstract}

\title{
Dinâmicas socializadoras e modos de individualização
}

Ao percorrer histórias, narrativas e práticas juvenis, os processos socializadores e de individualização podem ser tomados como dinâmicas imbricadas, simultâneas. Em outras palavras, partindo de uma perspectiva relacional entre as experiências em diferentes dimensões socializadoras (territórios, família, escola, trabalho, web, etc.), há um desafio no alcance da transversalidade desses espaços/processos na constituição dos/as jovens como sujeitos. No movimento da vida, há trabalho ativo dos/as jovens, diante da tarefa individual de compor vínculos entre as diferentes experiências "[...] mesmo que submetidas a fortes tensões e contradições. $O$ indivíduo deve perceber-se como um vértice relacional e produzir-se como um tecedor de relações". (ARAUJO, MARTUCCELLI, 2012, p. 246). Porém, antes de aprofundar sobre as possibilidades das sociologias do indivíduo, em que os sujeitos são vias relevantes para entender as sociedades contemporâneas, é oportuno esboçar algumas ponderações sobre o tema da socialização na produção sociológica.

Uma compreensão clássica, e que permanece guiando o entendimento da socialização, aparece na sociologia de Émile Durkheim que desenvolveu o conceito privilegiando o caráter externo e coercitivo da sociedade e a internalização pelos indivíduos de modos de comportamento e das moralidades sociais através dos processos educativos (DURKHEIM, 1955). A integração social, a manutenção do consenso e a sobrevivência das sociedades são algumas das funções sociais da socialização para Durkheim. Nessa dinâmica de interiorização do social, impetrada pelo processo de socialização, formam-se sujeitos que satisfazem às expectativas 


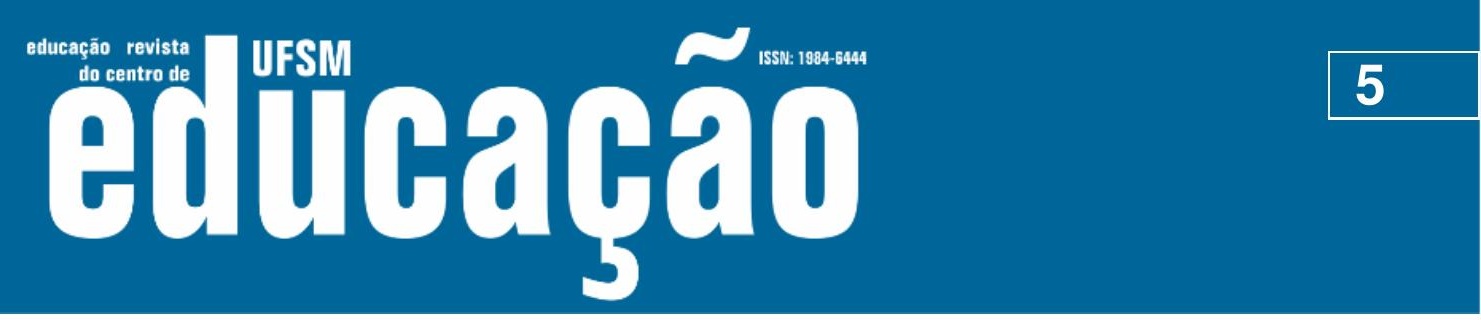

ISSN: 1984-6444 | http://dx.doi.org/10.5902/1984644439944

societárias. Nessa perspectiva, há evidente correspondência entre ator e sistema. Os indivíduos estão continuamente compelidos à ordem social. Em outras palavras, há pouco espaço para que os indivíduos se construam por escolhas autônomas e distantes das imposições institucionais. Os processos educativos são percebidos como procedimentos de uma geração já socializada, que incorporou os valores e comportamentos sociais, sobre as gerações mais jovens, ainda iniciantes na apreensão dos modos de conduta daquela sociedade. Por isso,

a educação é a ação exercida, pelas gerações adultas, sobre as gerações que não se encontrem ainda preparadas para a vida social. Tem por objetivo suscitar e desenvolver, na criança, certo número de estados físicos, intelectuais e morais, reclamados pela sociedade política. (DURKHEIM, 1955, p. 32).

Mesmo diante uma produção do final do século XIX e início do século XX, a partir da sociologia durkheimiana é possível refletir sobre o atual contexto em que as gerações mais novas têm maior domínio e habilidade no manuseio de artefatos tecnológicos digitais. A perspectiva do domínio das gerações mais velhas sobre as dinâmicas educativas apresenta limitações para a análise de processos de socialização atravessados pela internet, onde as relações de aprendizado, de como se construir online, como vivenciar e interagir no e com o ambiente digital, não são reguladas pelo domínio de uma geração mais velha ${ }^{3}$. A juventude é um símbolo no crescente processo de digitalização. O modelo da transmissão nas dinâmicas socializadoras é desestabilizado pelos saberes juvenis. As gerações mais novas interagem mais intensamente com as tecnologias e, nessa combinação, se produzem, orientam seu comportamento, gerem a própria existência. Nesse sentido, crianças e jovens revelam-se como sujeitos mais habilitados para instruir ou informar as lógicas de interação na cibercultura.

Perante a análise funcionalista durkheimiana, que privilegia a sociedade em face dos indivíduos, é condizente ponderar que as teorizações são construídas na disputa por maneiras de conceber as ciências sociais, além de relacionarem-se com o tempo histórico subjacente às análises ${ }^{4}$. Por um lado, a existência de teorias que abordam as instituições e a sociedade como elementos estruturantes da vida coletiva e, por outro, compreensões que dão relevância ao indivíduo enquanto eixo norteador, 


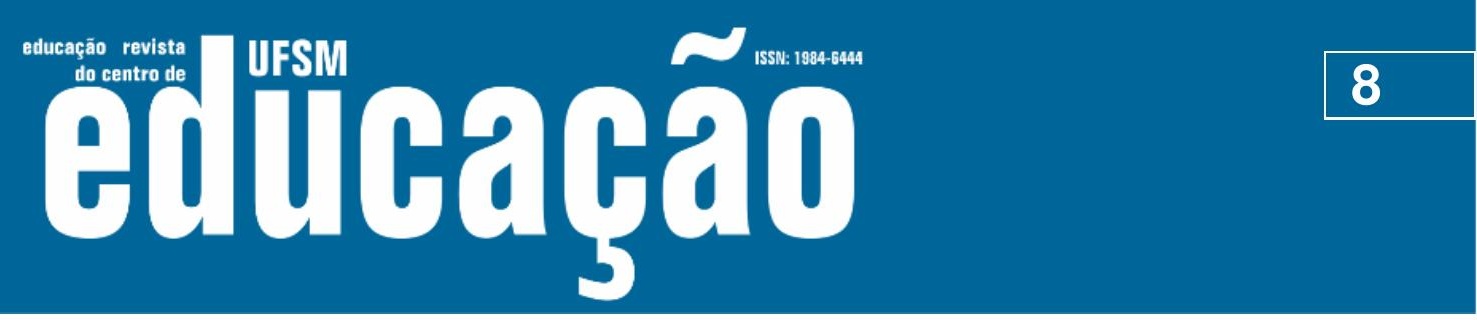

ISSN: 1984-6444 | http://dx.doi.org/10.5902/1984644439944

[...] o conceito de configuração foi introduzido exatamente porque expressa mais clara e inequivocamente o que chamamos de 'sociedade', que os atuais instrumentos conceituais da sociologia, não sendo nem uma abstração de atributos de indivíduos que existem sem uma sociedade, nem um 'sistema' ou 'totalidade' para além dos indivíduos, mas a rede de interdependência por eles formada. (ELIAS, 1994, p. 249)

A ideia de configuração ilustra as amplas possibilidades de traçado das redes de indivíduos. Em outras palavras, de diferentes modos as pessoas podem estar ligadas umas às outras e aos espaços, uma vez que as posições dos sujeitos nas tramas de interação são fluidas e mutáveis. Assim, configuração é instrumento conceitual conveniente para apreensão das contemporâneas e multifacetadas dinâmicas de socialização e individualização juvenis. Tanto rede como configuração são conceitos que possibilitam o olhar para os desenhos da dinamicidade de encontros e vivências em espaços como a família, o trabalho, a escola, os territórios da cidade, a internet e a singularidade dos modos de vida nessas instâncias. Assim, a ideia da transversalidade de experiências juvenis enredadas, não limita o significado da expressão rede exclusivamente à web. Como bem diz Bruno Latour (2012, p. 189), um bom relato de pesquisa é aquele que tece uma rede, em que "os atores tornam visível ao leitor o movimento do social" 5 .

Buscando modos de avistar os processos educativos e socializadores na atualidade, Graça Setton (2013) aproxima as reflexões de Norbert Elias e Marcel Mauss como pensadores que provocaram olhares sobre a condição plural dos indivíduos. Setton compreende que os conceitos fato social total, de Mauss, e configuração, de Elias, permitem o alcance da coexistência e encadeamentos entre as instâncias socializadoras e a constituição dos indivíduos na amálgama de dimensões transversais. A autora realça a potência do pensamento de Elias e Mauss para a compreensão dos modos de socialização e individualização numa perspectiva dialógica e relacional. Afinal, as "formulações dos autores salientam os processos socializadores como um campo de investigação que mistura fundamental e concomitantemente estruturas, atores, sentido e história" (SETTON, 2013, p. 206).

Portanto, em termos metodológicos e conceituais, os estudos com jovens podem articular múltiplas dimensões das experiências juvenis, a partir de pontos de vista construídos pelos próprios sujeitos. Uma vez que, como lembra Marcel Mauss 


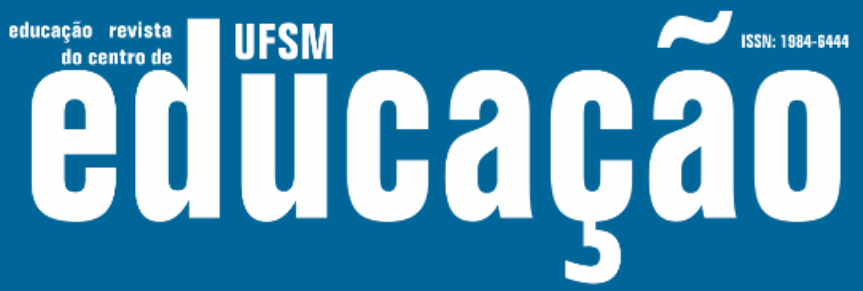

ISSN: 1984-6444 | http://dx.doi.org/10.5902/1984644439944

(1974, p. 181), "mais do que ideias ou regras, apreendem-se homens [mulheres], grupos e seus comportamentos" há potência na pesquisa com jovens que acompanham suas experiências e narrativas entrelaçadas ao universo da internet. Usando as palavras de Bernard Lahire a aposta está em esforços investigativos que não negligenciam "as bases individuais do mundo social, e que estuda, assim, indivíduos atravessando cenários, contextos, campos de força etc., diferentes" (LAHIRE, 2005, p. 31, 32).

\section{As sociologias do indivíduo como sensibilidade intelectual}

Ao projetar a relevância de uma abordagem que salienta indivíduos enredados em múltiplas experiências, é fundamental destacar a especificidade do fenômeno da individualização contemporânea. Mesmo que a sociologia sempre tenha se interessado pelo indivíduo, é de outro tipo a centralidade dos sujeitos na análise sociológica contemporânea (MARTUCCELLI, 2007a). Se na sociologia clássica a imagem do "personagem social" dominava a compreensão dos indivíduos, ou seja, havia expectativa de compreender o indivíduo a partir do conhecimento de sua posição ou classe social, hoje, avista-se uma crescente singularização dos indivíduos, "atores que se concebem e atuam como sendo 'mais' e 'outra coisa' que aquilo que supõe o que Ihes dita sua posição social. Os indivíduos se rebelam contra as classificações sociológicas." (MARTUCCELLI, 2007a, p. 8).

Cada indivíduo é fruto de uma série cada vez mais contingente e diversa de experiências de socialização. Assim, os processos de socialização contemporâneos são simultaneamente processos de individualização, inclusive porque, na "modernidade reflexiva", "segunda modernidade" (GIDDENS, BECK, LASCH 1997) ou "modernidade líquida" (BAUMAN, 2001), as próprias instituições encarregam os atores da responsabilização de suas trajetórias. As instituições não se limitam a exercer imposições aos indivíduos, mas avistam-se também como recursos que os sujeitos precisam aprender a mobilizar eficazmente, em outras palavras, elas são coercitivas e facilitadoras. (DUBAR, 2009). Por isso, "a maneira como se vive tornase uma solução biográfica das contradições sistêmicas" (BECK, 1992, p. 137 apud 


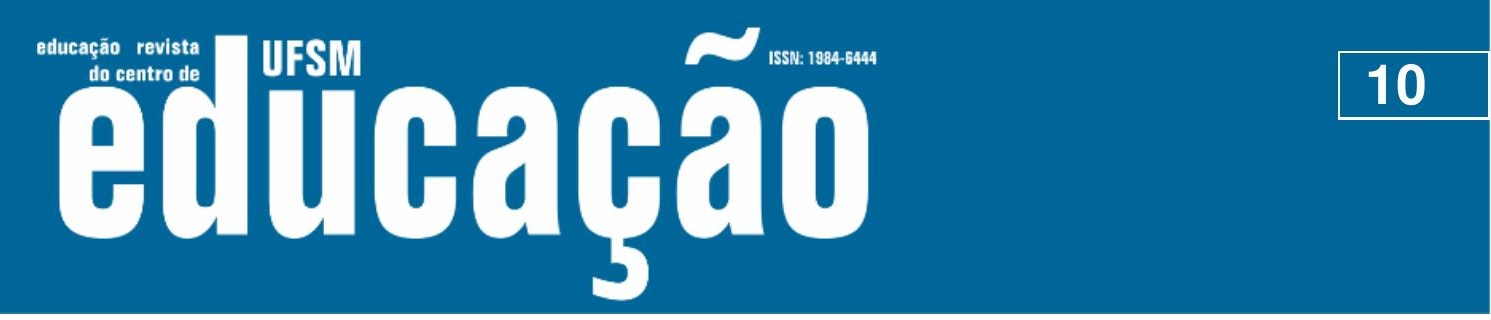

ISSN: 1984-6444 | http://dx.doi.org/10.5902/1984644439944

BAUMAN, 2001). Os riscos e as contradições são socialmente produzidos, mas o dever de enfrentá-los é individualizado. Por isso,

A individualização significa, potencialmente, a preeminência crescente dos
Eus sobre os Nós, a participação ativa dos cidadãos naquilo que lhes diz
respeito, a consideração das identidades pessoais nas decisões coletivas.
Pode-se considerar que ainda estamos muito longe disso. Mas esse é um
processo lento, complexo e incerto, que envolve cada nova geração no
desenrolar individual e coletivo de sua socialização, que é também
individualização. (DUBAR, 2009, p. 260 - grifos do autor)

Além disso, as experiências de socialização são estruturais e contingentes, diversas e desiguais, comprometendo a formação das individualidades. Variadas dinâmicas socializadoras estruturadas pelo machismo e racismo, comprometem desigualmente os modos de individualização. Reflexões recentes acerca da produção da diferença e da análise da desigualdade social vêm investindo na articulação dos marcadores sociais da diferença (MOUTINHO, 2014). Kimberlé Crenshaw (2002) aponta as várias formas pelas quais as experiências e vulnerabilidades de raça e gênero podem se entrecruzar. A autora destaca a invisibilidade interseccional quando categorias amplas (para ilustrar no campo de estudos de juventude, a identificação "jovens mulheres”, por exemplo) não alcançam as diferenças intragrupo. A sociologia dos indivíduos se complexifica diante de uma perspectiva que revela e analisa a interseccionalidade a partir de descrições mais precisas das experiências transversalizadas de raça, gênero, classe, geração, território e sexualidade ${ }^{6}$.

A compreensão da socialização como reprodução social é limitada para a investigação dos processos socializadores contemporâneos. Segundo Dubet (1994), tendo em vista a desinstitucionalização dos modos de produção dos indivíduos, a formação dos sujeitos depende cada vez menos dos moldes impostos pelas instituições e pelos seus papéis, e cada vez mais das experiências individuais. Em outras palavras, não há adequação irrestrita entre a subjetividade do ator e a objetividade do sistema, pois a experiência social é concebida como uma atividade dos indivíduos, uma capacidade crítica e um distanciamento de si mesmos. Nessa perspectiva, a noção de experiência considera a heterogeneidade dos princípios culturais e sociais que organiza as condutas em uma sociedade: "O sujeito social é definido por um jogo de tensões, por um trabalho e não por um ser." (DUBET, 1994, 


\section{Hsm Eulloarat}

ISSN: 1984-6444 | http://dx.doi.org/10.5902/1984644439944

p. 260). Por isso a necessidade da sociologia voltar-se para a experiência de indivíduos particulares que constroem seu mundo e sua individualidade numa história singular. Os processos de construção do significado da experiência são cada vez mais uma prerrogativa das pessoas. É por isso que o autor considera os indivíduos "intelectuais" na medida em que operam de maneira reflexiva sua relação com o mundo. Assim, no campo de produção dos estudos de juventude, destaca-se a importância de pesquisas que alcancem as narrativas jovens já que "o que se conhece da experiência é aquilo que dela é dito pelos actores, este discurso vai colher as categorias sociais da experiência" (DUBET, 1994, p. 103).

No campo da sociologia da educação e juventude, Marília Spósito (2003) em texto que já anuncia em seu título uma perspectiva não escolar no estudo sociológico da escola, também inspira um deslocamento do olhar institucional para a complexidade de relações dos sujeitos entre múltiplas agências socializadoras. Tendo em vista o processo de desinstitucionalização escolar, os/as jovens se esforçam para se construírem como sujeitos em um trabalho sobre si mesmos/as. Por isso, a autora convoca a passagem de uma sociologia da escolarização (que privilegia o campo institucional) para uma sociologia da socialização (SPOSITO, 2003). As pesquisas com jovens são desafiadas a desescolarizar suas abordagens, ultrapassando os limites das vivências juvenis à instituição, ampliando uma pluralidade de espaços, a partir das experiências dos sujeitos.

Danilo Martuccelli (2007a) propõe que a sociologia centralize a individuação como maneira de investigar os processos de fabricação dos indivíduos. O autor defende a particularidade dessa perspectiva analítica que se interroga pelo tipo de indivíduo (e poderíamos delimitar, que tipo de jovem) é estruturalmente fabricado por uma sociedade em um período histórico. A concepção de individuação cruza, portanto, um eixo sincrônico e outro diacrônico na medida em que as grandes transformações históricas precisam ser percebidas através das experiências dos indivíduos.

$\mathrm{Na}$ busca por compreender os diferentes modos de individuação, Araújo e Martuccelli desenvolvem o conceito de prova também identificado por desafio. Esse operador analítico remete "aos desafios históricos, socialmente produzidos, 


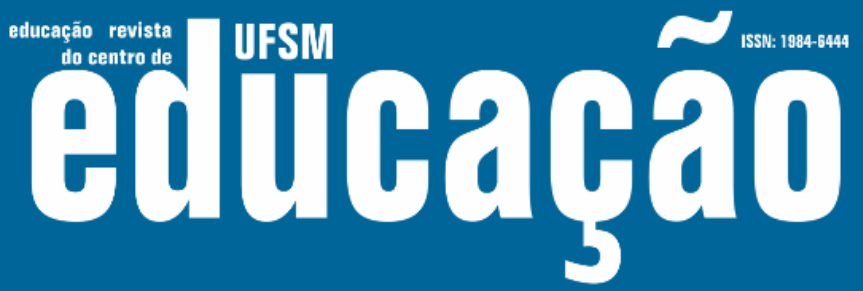

ISSN: 1984-6444 | http://dx.doi.org/10.5902/1984644439944

culturalmente representados, desigualmente distribuídos que os indivíduos estão obrigados a enfrentar" (ARAÚJO; MARTUCCELLI, 2010, p. 83). A partir dessa noção, os autores conjeturam a percepção da vida social em sua elasticidade, indicando a articulação entre processos sociais e experiências pessoais, a história da sociedade e a constituição dos indivíduos. As provas não são qualquer tipo de problema vivencial, mas um conjunto de desafios estruturais (escolares, laborais, relacionais) e por isso comum a todos os indivíduos de um coletivo, que por sua vez, percebem e respondem aos desafios de maneiras diversas ${ }^{7}$. Portanto, as provas se articulam aos processos de socialização, já que são vivenciadas em espaços institucionais (escola, trabalho, família) ou são relativas ao laço social (participação em grupos, uso do tempo, relações interpessoais).

Entende-se que a maneira particular pela qual cada pessoa "resolve" os desafios que enfrenta nos processos socializadores permite o contorno de sua singularização. A sociologia do indivíduo viabiliza o alcance das trajetórias vividas de maneira fortemente singular, atravessadas por dificuldades e êxitos, destino e sorte, oportunidades e dominações. (ARAUJO; MARTUCCELLI, 2010). A compreensão da individualização pelas provas é caminho investigativo para atingir o trabalho pessoal de cada indivíduo em responder aos desafios, vivenciar processos socializadores e fabricar-se como sujeito ${ }^{8}$.

Por isso, as pesquisas com jovens se potencializam quando multifocalizadas e alcançam sujeitos em processos socializadores online e offline, heterogêneos, fluidos, em tensão e constante movimento. A constituição dos/as jovens como sujeitos está comprometida com uma multiplicidade de repertórios sociais diferenciados, coerentes ou contraditórios (LAHIRE, 2005). Na rede plural de hipertextualidade (PAIS, 2001) vivenciada e tecida pelos/as jovens, é imprescindível atentar para imbricadas relações entre as dinâmicas online e outras agências socializadoras. As juventudes contemporâneas - como geração @ (FEIXA, 2006) - habitam o ciberespaço e constroem modos de ser que acenam para múltiplas articulações entre vida e relato audiovisual que se fundem e se confundem nas biografias em textura informática (SIBILIA, 2018). Assim, se o ciberespaço é entendido como matriz de socialização, ele também precisa ser alcançado em sua transversalidade, na medida em que as 


\section{Autตaดูão}

ISSN: 1984-6444 | http://dx.doi.org/10.5902/1984644439944

intimamente ligadas com o interesse de "controlar a capacidade de definir as regras e normas da sociedade mediante um sistema político que responde basicamente a seus interesses e valores" (CASTELLS, 2013, p. 16). Entretanto, é o próprio autor que vislumbra que a autocomunicação de massa fornece algumas possibilidades de autonomia dos usuários, individuais e coletivos. $\mathrm{O}$ autor destaca que as redes sociais digitais oferecem a possibilidade de deliberar e coordenar ações sem grandes impedimentos.

Diante de múltiplas plataformas, meios e recursos de comunicação na web, são as chamadas redes sociais digitais as mais populares nas vivências cotidianas juvenis. Facebook, Twitter, Instagrame YouTube são as mais usadas na atualidade ${ }^{11}$. Há uma dinâmica semelhante que opera nessas plataformas digitais em que os/as usuários/as constroem e mantêm uma conta/perfil que se vincula a outros/as usuários/as. O perfil é construído através de um procedimento de personalização naquele espaço onde, ao expor suas preferências, vídeos, imagens e outros recursos, o/a usuário/a passa a existir enquanto pessoa no contexto da plataforma "adensando sua presença" (ALMEIDA; EUGÊNIO, 2006). Parece haver uma maximização dos indivíduos através de ferramentas on-line que possibilitam uma exposição de atributos pessoais de suas vivências nos múltiplos espaços pelos quais circulam e expõem na rede, em constante e diária construção. O imperativo da visibilidade opera através das performances, narração de múltiplas experiências e da construção de si (SIBILIA, 2012).

Frente às incontáveis possibilidades de peças para a arquitetura da experiência virtual, na construção de sujeitos, comunidades e agrupamentos online, no ciberespaço podemos (re)configurar o social e o individual; aglutinar pessoas aliadas por uma variedade de coletivos referenciados em qualidades, preferências, espaços, pertencimentos e gostos. Assim, diante de duas possibilidades de olharmos as culturas juvenis, "através das socializações que as prescrevem ou das suas expressividades (performances) cotidianas" (PAIS, 2006, p. 7), José Machado Pais, a partir da conceituação dos espaços "lisos" e "estriados" de Deleuze e Guattari (1997), propõe: 


\section{Autharão}

ISSN: 1984-6444 | http://dx.doi.org/10.5902/1984644439944

entrelaçam nas vivências juvenis? Plataformas e recursos online são espaços de socialização e podem servir como suportes para individualização? Tais perguntas podem inspirar as pesquisas contemporâneas com jovens que se desafiam a compreender os modos de vida juvenis em contexto de ampla conexão online.

Partindo do entendimento de que "são os próprios indivíduos quem tecem as redes de sentido que os unificam em suas experiências de socialização" (SETTON, 2009, p. 297); as pesquisas com jovens se potencializam quando elucidam formas de socialização/individualização dos sujeitos em seus multipertencimentos, em experiências online e face a face. A internet é espaço de hipertextualidade e convergência. O universo online é domínio privilegiado da experiência contemporânea, principalmente juvenil. Novos desafios para as pesquisas com jovens e suas práticas emergem nesse contexto. Múltiplas dobras entre espaço público e ciberespaço se evidenciam na contemporaneidade. A internet é vetor transversal no cotidiano, dimensão que pode estar tangenciada de diversas maneiras, inclusive combinada a espaços estriados (como a família, a escola e o trabalho). A web, principalmente através das redes sociais digitais, é espaço regular nos movimentos de singularização de jovens, com marcas de reflexão, expressividade, criatividade, denúncia, compartilhamento, visibilidade, performance. As pesquisas com jovens podem alcançar e articular análises sobre as narrativas orais e digitais, buscando o encontro da sociologia dos sociólogos com a sociologia dos atores. (DUBET, 1994).

Tramar perspectivas de sociologias da juventude em rede pode revelar como os/as jovens ligam os pontos, tecem suas redes, reconfigurando-as ao longo de suas trajetórias, em um trabalho sobre si mesmos. Diante de tais problematizações, a tríade socialização/individualização/rede pode inspirar pesquisas que buscam a "transversalidade no estudo sobre jovens" (SPOSITO, 2010). Há potência em compreender as construções dos/as jovens considerando-os/as como sujeitos que criam singularmente suas histórias e refletem sobre elas, inclusive no ciberespaço. 


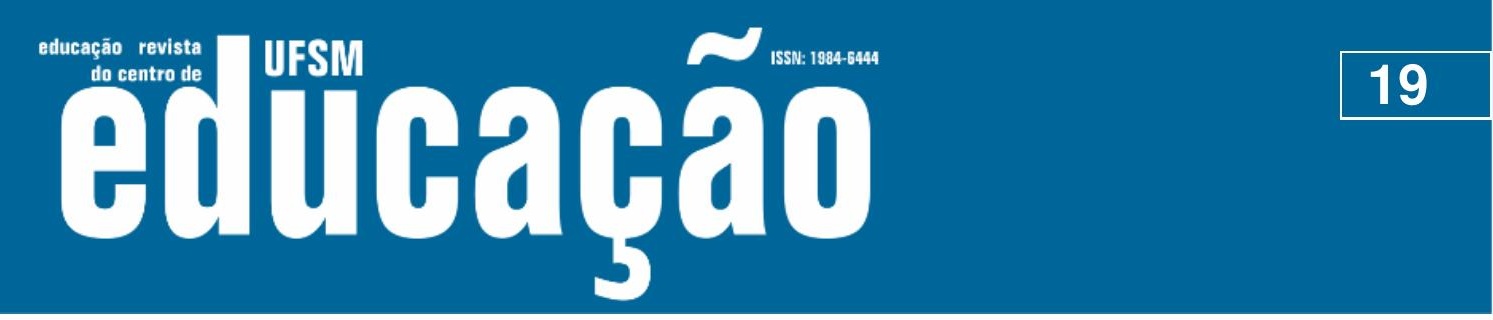

ISSN: 1984-6444 | http://dx.doi.org/10.5902/1984644439944

\section{Referências}

ALMEIDA, Maria; EUGÊNIO, Fernanda. O espaço real e o acúmulo que significa: uma nova gramática para se pensar o uso jovem da internet no Brasil. In: NICOLACI-DA COSTA, A. (Orgs.) Cabeças digitais: o cotidiano na era da informação. 1 ed. São Paulo, Loyola, 2006.

ARAUJO, Kathya; MARTUCCELLI, Danilo. La individuación y el trabajo de los indivíduos. Educação e Pesquisa, São Paulo, v.36, n. especial, p. 77-91, 2010.

ARAUJO, Kathya; MARTUCCELLI, Danilo. Desafios comunes: Retrato de la sociedad chilena y sus indivíduos. Tomo 1. Santiago: LOM Ediciones, 2012.

BAUMAN, Zygmunt. Modernidade líquida. Rio de Janeiro: Jorge Zahar, 2001

BERGER, Peter; LUCKMANN, Thomas. A construção social da realidade. Petrópolis: Vozes, 1995.

CAMPOS, Antonia M.; MEDEIROS, Jonas; RIBEIRO, Márcio M. Escolas de luta. São Paulo: Veneta, 2016.

CRENSHAW, Kimberle. Documento para o encontro de especialistas em aspectos da discriminação racial relativos ao gênero. Revista Estudos Feministas, Florianópolis, UFSC, p.171-188, 2002.

CASTELLS, Manuel. A Era da Informação: A Sociedade em Rede. V1. São Paulo: ed. Paz e Terra, 1999.

CASTELLS, Manuel. Redes de Indignação e Esperança: Movimentos sociais na era da internet. Rio de Janeiro: Zahar, 2013.

DELEUZE, Gilles; GUATTARI. Mil Platôs, capitalismo e esquizofrenia. Rio de Janeiro: Editora 34, 1997.

DIÓGENES, Gloria. Signos urbanos juvenis: rotas da piXação no ciberespaço. Cadernos de Campo, v. 22, p. 45-61, 2014.

DUBAR, Claude. A crise das identidades: a interpretação de uma mutação. São Paulo: Editora da Universidade de São Paulo, 2009.

DUBET, François. Sociologia da Experiência. Lisboa: Instituto Piaget, 1994.

DURKHEIM, Émile. Educação e Sociologia. São Paulo: Melhoramentos, 1955.

ELIAS, Norbert, A sociedade dos indivíduos. Rio de Janeiro: Jorge Zahar, 1994. 


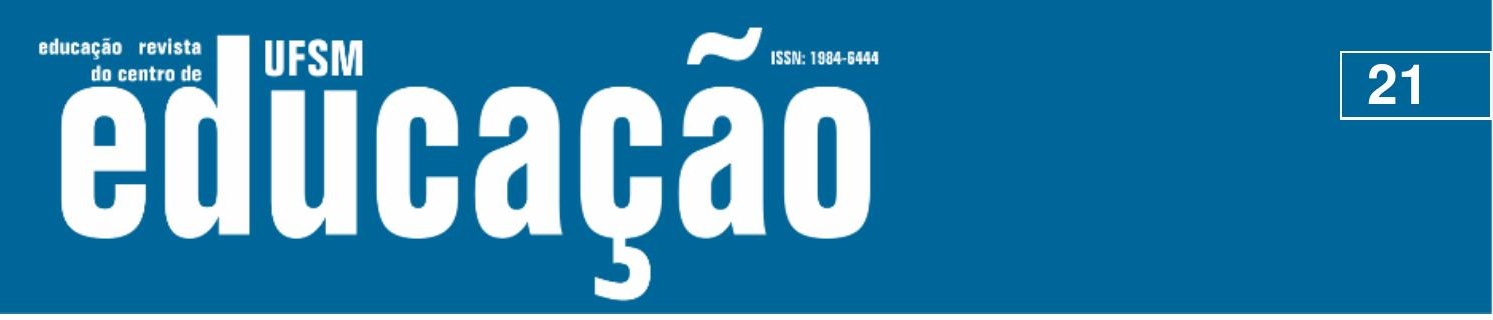

ISSN: 1984-6444 | http://dx.doi.org/10.5902/1984644439944

PAIS, José Machado. Buscas de si: expressividades e identidades juvenis. In: ALMEIDA, M; EUGENIO, F. (Org.) Culturas Jovens: novos mapas do afeto. Rio de Janeiro: Jorge Zahar Editor, 2006, p.7-21.

PELUCIO, Larissa. Na noite nem todos os gatos são pardos: notas sobre a prostituição travesti. Cad. Pagu, Campinas, n. 25, p. 217-248, 2005.

PEREIRA, Alexandre Barbosa. "A maior zoeira": experiências juvenis na periferia de São Paulo. Tese de doutorado. São Paulo: USP/ Programa de Pós-Graduação em Antropologia Social. 2010.

REIS, Juliana Batista dos. Transversalidade nos modos de socialização e individuação: experiências juvenis em rede. Tese de doutorado. Belo Horizonte: UFMG Programa de Pós-Graduação em Educação, 2014.

REIS, Juliana Batista dos; DAYRELL, Juarez. Uma jovem negra favelada: singularidade compartilhada em narrativas biográficas. Debates em educação, Maceió, v. 10, n.20, p.83-99, Abr. 2018. Disponível em: Disponível em: http://www.seer.ufal.br/index.php/debateseducacao/article/view/4041 Acesso em: 19 fev. 2020.

SERRES, Michel. Polegarzinha. Rio de Janeiro: Bertrand Brasil, 2013.

SETTON, Maria da Graça Jacintho. Marcel Mauss e Norbert Elias: notas para uma aproximação epistemológica. Educ. Soc., Campinas , v. 34, n. 122, p-195210, mar. 2013

Disponível em http://www.scielo.br/scielo.php?script=sci_arttext\&pid=S0101-

$73302013000100011 \& \operatorname{lng}=$ pt\&nrm=iso Acesso em: 10 jan. 2019.

SETTON, Maria da Graça Jacintho. A socialização como fato social total: notas introdutórias sobre a teoria do habitus. Rev. Bras. Educ., Rio de Janeiro, v. 14, n. 41, p. 296-307, Ago. 2009. Disponível em: http://www.scielo.br/scielo.php?script=sci_arttext\&pid=S1413-

$24782009000200008 \&$ Ing=en\&nrm=iso Acesso em: 10 jan. 2019.

SIBILIA, Paula. Redes ou paredes: a escola em tempos de dispersão. Rio de Janeiro: Contraponto, 2012.

SIBILIA, Paula. Você é o que Google diz que você é: A vida editável, entre controle e espetáculo. Intexto: Revista do PPGCOM-UFRGS, n. 42, Porto Alegre, Brasil, p. 214231, Maio/Ago. 2018.

SPOSITO, Marilia Pontes. Transversalidades no estudo sobre jovens no Brasil: educação, ação coletiva e cultura. Educ. Pesqui., São Paulo, v. 36, n. spe, p. 95106, $2010 . \quad$ Disponível em: http://www.scielo.br/scielo.php?script=sci_arttext\&pid=S1517$97022010000400008 \&$ Ing=en\&nrm=iso Acesso em: 10 jan. 2019. 


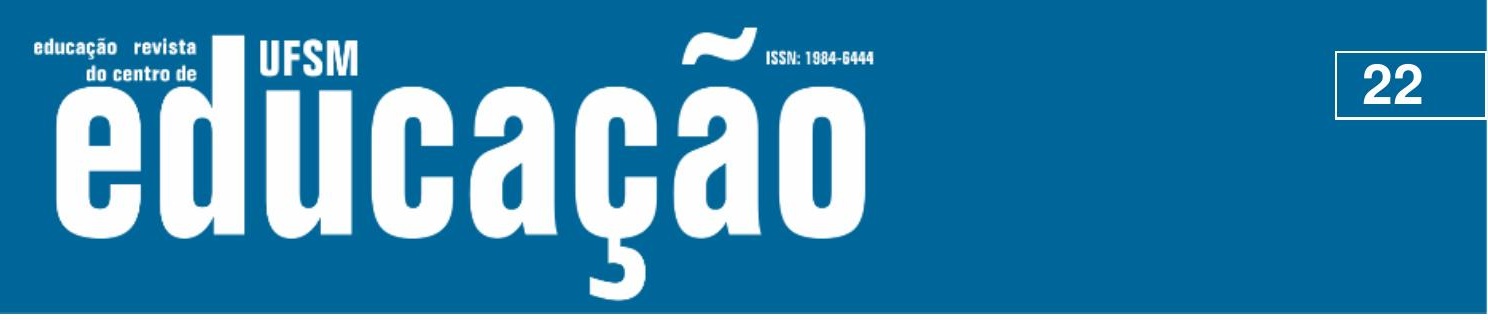

ISSN: 1984-6444 | http://dx.doi.org/10.5902/1984644439944

SPOSITO, Marilia Pontes. Uma perspectiva não escolar no estudo sociológico da escola. REVISTA USP, São Paulo, n.57, p. 210-226, p. 210-226, março/maio 2003. Disponível em: http://www.revistas.usp.br/revusp/article/view/33843/36576 Acesso em: 10 de jan.2019.

\title{
Correspondência
}

Juliana Batista dos Reis -Universidade Federal de Minas Gerais - Av. Pres. Antônio Carlos, 6627 - Pampulha, CEP 31270-901, Belo Horizonte, Minas Gerais. Brasil.

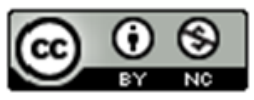

This work is licensed under a Creative Commons Attribution-NonCommercial 4.0 International (CC BY-NC 4.0)

\section{Notas}

\begin{abstract}
${ }^{1}$ As reflexões teóricas deste ensaio se embasam em um percurso de pesquisa empírica com jovens. A investigação foi financiada pela Coordenação de Aperfeiçoamento de Pessoal de Nível Superior (CAPES).

2 Danilo Martuccelli (2018) propõe uma distinção entre os conceitos individuação e individualização. A ideia de individuação remete à busca de identificação dos tipos de indivíduos que são fabricados estruturalmente em determinada sociedade, a partir da análise socio-histórica. Já individualização designa os processos de diferenciação ou singularização interindividual presentes em uma sociedade. Apesar da estreita relação entre os termos, esse texto destaca um determinado empreendimento de pesquisa que alcança as singularidades juvenis, os modos de ser jovem. Contudo, não se descarta a relevância de análises macroestruturais que revelam os tipos de indivíduos fabricados estruturalmente, como a pesquisa de Kátia Araújo e Danilo Martuccelli sobre a sociedade chilena (2012).
\end{abstract}

${ }^{3}$ Em algumas produções acadêmicas e jornalísticas a expressão "nativos digitais" tem sido utilizada para sinalizar as gerações nascida na era da internet. Assim, os "imigrantes digitais" seriam os mais velhos, aqueles que precisam se esforçar para se adaptarem ao ambiente digital. Outras expressões como 'geração x, y e z' operacionalizam a identificação de grupos geracionais no universo digital. Apesar da não existência de um consenso, geralmente se nomeia as pessoas nascidas entre os anos de 1980 e 1990 como pertencentes à geração x e y, respectivamente. Enquanto aqueles nascidos a partir dos anos 2000 como geração z.

${ }^{4}$ Nesse sentido, Bruno Latour (2012) aponta Durkheim como um pensador “vencedor" na disputa pela construção sociológica na relação com Gabriel Tarde.Tarde criticou as compreensões durkheimianas sobre a ideia de que a sociedade era um domínio especial da realidade. Latour considera Tarde um precursor da "Teoria Ator Rede" (proposta de investigação de Latour que agrega a relação entre humanos e não humanos) visto que "ele sustentou veementemente que o social não era domínio especial da realidade e sim um princípio de conexões; que não havia motivo para separar o 'social' de outras associações como os organismos biológicos ou mesmo os átomos. (2012, p. 33)".

${ }^{5}$ Bruno Latour (2012) problematiza a imprecisão terminológica do termo rede. As redes podem ter um sentido técnico (eletricidade, sistema metroviário, rede de esgoto e mesmo a internet) e/ou significar as associações humanas. Entretanto, na proposta de Latour de desenvolver uma "sociologia das associações" a partir da Teoria 


\section{N Wrsm

ISSN: 1984-6444 | http://dx.doi.org/10.5902/1984644439944

Ator-Rede, outros agentes não humanos são considerados como atores ou "actantes". "Uma vez que em inglês, a palavra 'actor' (ator) se limita a humanos, utilizamos muitas vezes 'actant' (actante), termo tomado à semiótica para incluir não humanos na definição” (LATOUR, 2001, p. 346).

${ }^{6}$ No texto "Uma jovem mulher negra favelada: singularidade compartilhada em narrativas biográficas" (REIS; DAYRELL, 2018) privilegiamos a análise à escala individual de uma jovem moradora da cidade de Belo Horizonte que vive os desafios da interseccionalidade raça, gênero e classe em experiências socializadoras familiares, escolares e profissionais. Sua experiência online explicita com recursos múltiplos (imagens, fotos, frases, textos) a reflexividade e a combatividade decorrentes de processos de enfrentamento da pobreza, do racismo e do machismo. Suas postagens mencionam os estigmas, as desigualdades, as violências frequentes, mas também expressam sua forte identidade como negra e favelada.

${ }^{7}$ Nos limites desse texto não será possível explorar outro operador analítico desenvolvido por Martuccelli (2007b), os suportes. O conceito designa apoios que podem ser materiais, simbólicos, conscientes ou inconscientes, ativamente estruturados ou não, mas sempre têm o efeito de sustentar e fomentar os processos de individuação. A própria internet pode operar como suporte da singularização de jovens.

${ }^{8}$ Martuccelli e Singly (2012) repercutem variadas possibilidades teórico-metodológicas de pesquisas no campo das sociologias do indivíduo e caracterizam as distintas perspectivas analíticas.

${ }^{9}$ Um exemplo bastante comum são os agrupamentos online no Facebook ou no aplicativo para celulares Whats'app que reúne estudantes de uma mesma escola ou classe escolar. Por outro lado, podem-se alcançar experiências juvenis exclusivas ao universo online, sem intermediação face a face.

${ }^{10}$ Em nossa pesquisa, um dos jovens participantes revelou fortes marcas das experiências socializadoras familiares em dinâmicas online. Por exemplo, em ambientes digitais as fotografias familiares estampavam as relações afetuosas de respeito e admiração pelo pai e a mãe, os acontecimentos no âmbito familiar eram exibidos e acompanhados de textos que afirmavam os carinhosos laços de filiação. (REIS, 2014)

11 Verifica-se um movimento de obsolescência das mídias digitais. Em outros tempos, tão populares, alguns recursos deixaram de existir, como Orkut, Myspace, Fotolog, Formspring, ICQ, Snapchat.

12 Outro campo de reflexão da investigação com jovens na internet relaciona-se aos limites e possibilidades dos encontros de pesquisa na web, os princípios éticos do uso de imagens, privacidade dos/as interlocutores/as, entre outros aspectos. 